\title{
BEHAVIOUR OF FIBRE REINFORCED HONEYCOMB CORE UNDER LOW VELOCITY IMPACT LOADING
}

\author{
Giuseppe Petrone ${ }^{*}$, Sanjeev Rao $^{\dagger}$, Sergio De Rosa ${ }^{*}$, Brian Mace ${ }^{\dagger}$, Debes Bhattacharyya ${ }^{\dagger}$ \\ * Università degli studi di Napoli Federico II \\ Aerospace Engineering Department \\ via Claudio 21, 80125 Napoli, Italy \\ e-mail: giuseppe.petrone@unina.it \\ $\dagger$ The University of Auckland \\ Centre for Advanced Composite Materials, Mechanical Engineering Department \\ Private Bag 92019, Auckland, New Zealand \\ e-mail: s.rao@auckland.ac.nz
}

Key words: Honeycomb, Fibre reinforced core, Impact analysis

In this study, the behaviour of three different types of cores, commercially available unreinforced polymeric core, short flax fibre reinforced and continuous flax fibre reinforced polymeric cores under low velocity out-of-plane impact loads has been investigated. The fibre reinforced corrugations were manufactured using matched-die compression moulding and the resulting cell walls were bonded using ultrasonic methods to form recyclable honeycomb cores, in effect rendering them environment friendly. Imatek IM10T-20 ITS drop weight impact tester, capable of producing velocities of up to $20 \mathrm{~m} / \mathrm{s}$ coupled with Phantom high speed camera was used to capture video of the impact. The displacement of the impactor was recorded with a digital displacement transducer and the force was recorded with a digital force transducer. The initial test results of unreinforced polymeric cores under an impact energy of $15 \mathrm{~J}$ reveals buckling of the cell walls followed by crack developing at the double cell wall interface as early as $0.5 \mathrm{~ms}$ after impact, growing up to maximum length of approximately $10 \mathrm{~mm}$ (half the height of the core) within $3.5 \mathrm{~ms}$ (Fig.1). The majority of the deformation was observed at the contact points, with all of the deformation occurring in the middle of the core.
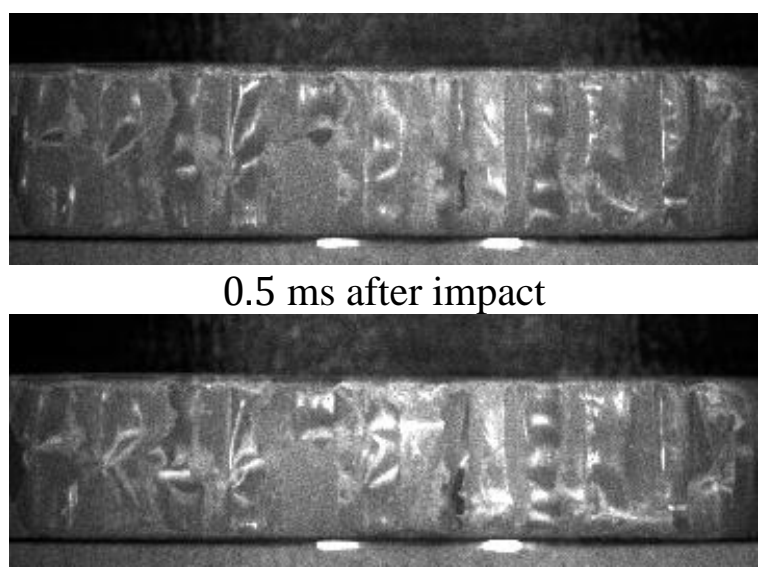

$2.5 \mathrm{~ms}$

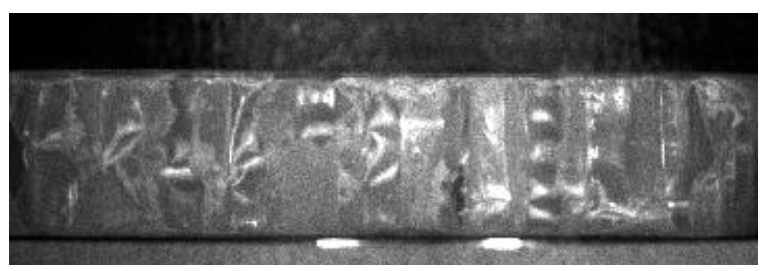

$1.5 \mathrm{~ms}$

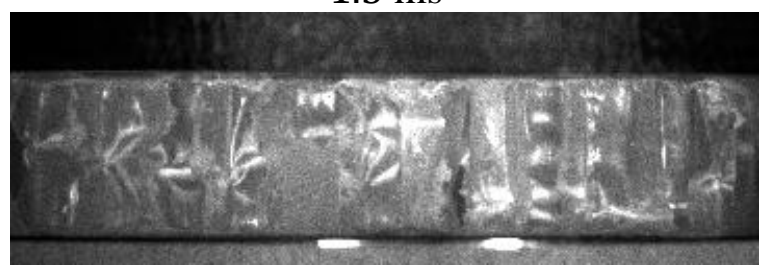

$3.5 \mathrm{~ms}$

Figure 1 Polymeric core subjected to $15 \mathrm{~J}$ out-of-plane impact loading 


\section{REFERENCES}

[1] M.A. Hazizan and W.J. Cantwell, The low velocity impact response of an aluminium honeycomb sandwich structure. Composites: Part B, (2003).

[2] M. Yamashita and M. Gotoh, Impact behavior of honeycomb structures with various cell specifications - numerical simulation and experiment. International Journal of Impact Engineering, (2004).

[3] S. Deqiang, Z. Weihong and W. Yanbin, Mean out-of-plane dynamic plateau stresses of hexagonal honeycomb cores under impact loadings. Composite Structures, (2010). 